\title{
HCV Therapy Follow-up Fractionation (CTF2) by Intra-PBMC Nested RNA PCR Recognizes Early Virologic Response and Relapse
}

\author{
Mohamed Darwish Ahmed Abd Alla*1, Saleh Ahmed Elibiary ${ }^{1}$, Ramy Hassan Elshaboury ${ }^{2}$, \\ George Y. Wu ${ }^{3}$, Reham M. Dawood ${ }^{4}$ and Mostafa Kamel El Awady ${ }^{4}$ \\ ${ }^{1}$ Tropical Medicine Department, Faculty of Medicine, Al-Azhar University, Cairo, Egypt; ${ }^{2}$ Department of Pharmacy, Massachusetts \\ General Hospital, Boston, MA, USA; ${ }^{3}$ Department of Medicine, Division of Gastroenterology-Hepatology, University of Connecticut \\ Health Center, Hartford, CT, USA; ${ }^{4}$ Department of Microbial Biotechnology, National Research Center, Cairo, Egypt
}

\begin{abstract}
Background and Aims: Sustained virologic response is evaluated by single-step reverse transcription (SRT) PCR assay, which assesses hepatitis $\mathrm{C}$ virus (HCV) clearance from plasma but not from tissues such as peripheral blood mononuclear cells (PBMCs). Persistence of HCV RNA in PBMCs beyond end of treatment (EOT) is associated with nonresponse. Our goal was to measure intra-PBMC HCV RNA levels during oral antiviral therapy according to the HCV therapy follow-up fractionation (CTF2) protocol. Methods: Compensated chronic HCV patients ( $n=278$ SRT-PCR positive) were scheduled to receive oral antiviral therapy. Subjects were followed-up by SRT and intra-PBMCs HCV RNA PCR at the end of the $2^{\text {nd }}, 6^{\text {th }}, 10^{\text {th }}, 14^{\text {th }}, 18^{\text {th }}$ and $24^{\text {th }}$ weeks to evaluate virus clearance from plasma and PBMCs, respectively. The CTF2 protocol evaluated SRT and PBMC PCR status at each follow-up point for determining therapy continuation or interruption to address cost effectiveness. Results: All patients tested negative by SRT PCR after therapy for 2 weeks. Application of the CTF2 protocol revealed: a) increasing HCV clearance rate from $75.9 \%$ at the end of $10^{\text {th }}$ week to $90.3 \%$ at the end of $24^{\text {th }}$ week $(p<0.00001)$; b) faster clearance of HCV from plasma compared to PBMCs at each point of follow-up until the $18^{\text {th }}$ week $(p<0.05)$; $)$ higher viral elimination rates diagnosed by PBMC HCV RNA PCR $(-)$ compared to PBMC HCV RNA PCR $(+)$ from the $6^{\text {th }}$ to $24^{\text {th }}$ week of treatment $(p<0.0001)$; $d)$ higher over-time increase curve of combined plasma and PBMC HCV RNA determined negativity compared to the decline in positivity curves by PBMC PCR at the $6^{\text {th }}-18^{\text {th }}$ week compared to the $24^{\text {th }}$ week $(p<0.01)$-these results validated treatment continuation; and e) solitary evaluation of EOT sustained HCV infection and relapses by PBMC HCV
\end{abstract}

Keywords: CTF2 protocol; HCV; PBMCs; PCR; Cost-effectiveness.

Abbreviations: CRS, cirrhosis risk score; CTF2, HCV-therapy follow-up fractionation; DAAs, direct-acting antiviral agents; EOT, end of treatment; EOTSCI, end of treatment sustained HCV infection; HCC, hepatocellular carcinoma; HCV, hepatitis $\mathrm{C}$ virus; OAT, oral antiviral therapy; OCI, occult HCV infection; PBMCs, peripheral blood mononuclear cells; RAS, resistance-associated substitution; SRT, single-step reverse transcription; SVR, sustained virologic response.

Received: 8 December 2017; Revised: 24 January 2018; Accepted: 9 February 2018

*Correspondence to: Mohamed Darwish Ahmed Abd Alla, Gouhar Al-Kaed Street, El-Hussein University Hospital, Al-Azhar University, Al-Darasah, Cairo 11675, Egypt. Tel: +20-109-417-5209, Fax: +20-25123091, E-mail: darwish0716@ azhar.edu.eg
RNA ( $p<0.001)$. Conclusions: Early elimination of serum and tissue (PBMC) HCV infection by oral antiviral therapy can be achieved and evaluated during a cost-effective CTF2 protocol application.

Citation of this article: Abd Alla MDA, Elibiary SA, Elshaboury RH, Wu GY, Dawood RM, El Awady MK. HCV therapy follow-up fractionation (CTF2) by intra-PBMC nested RNA PCR recognizes early virologic response and relapse. J Clin Transl Hepatol 2018;6(2):147-154. doi: 10.14218/JCTH.2017.00077.

\section{Introduction}

Worldwide, the highest prevalence of hepatitis C virus (HCV) genotype 4 infection was reported among the Egyptian population. According to the Egyptian Demographic Health Survey (2015), around $15 \%$ of the survey responders had anti-HCV IgG antibodies, whereas only $10 \%$ were found to have active infection. HCV patients are at risk for developing end-stage liver disease because of complications like hepatocellular carcinoma (HCC) and decompensated liver cirrhosis that may mandate liver transplantation. Chronic HCV infection is associated with an elevated risk for liver-related mortality. ${ }^{1,2}$ The relationship between the severity of HCVinduced liver cirrhosis and host genetics has been predicted by calculation of the cirrhosis risk score (CRS) that reflects variation in nucleotide sequences in a seven-gene signature. ${ }^{3}$ In previous studies, the association of increased prevalence of liver cirrhosis in peripheral blood mononuclear cell (PBMC) $\mathrm{HCV}$ infection were reported in nonviremic patients. ${ }^{4,5}$

Tracing efficacy of the current anti-HCV medications is now based solely on the sustained clearance of HCV RNA from sera for up to a minimum of 12 weeks. Despite high probabilities of cure rates in experienced HCV RNA seronegative patients after direct-acting antivirals (DAAs)-therapy, positive intracellular HCV RNA remains a good predictor of serologic relapse in posttreatment secondary experienced occult HCV infections. ${ }^{4-6}$ Furthermore, diagnosis and treatment of naïve patients who present with nonviremic intracellular HCV infections have not been included in the guidelines. These patients are liable to undergo HCV RNA seroconversion and have subsequent development of active liver cirrhosis. ${ }^{4,5}$ In addition, PBMC PCR was reportedly positive in $61 \%$ of cryptogenic $\mathrm{HCV}$ infections that presented with chronic hepatocellular dysfunction for more than 6 months and without any serologic evidence of viral infection. ${ }^{6}$ Because of the above-mentioned 
concerns, detection of HCV RNA in extrahepatic virotropic tissues may be helpful in predicting virological outcomes. Regrettably, PCR of tissue HCV RNA levels has not been used routinely in evaluation of treatment outcomes, despite the use of PBMC HCV RNA PCR is highly recommended during follow-up after treatment and before establishing the sustained virological response (SVR). ${ }^{4,5}$

Based upon clinical (evidence or observations) practice, some patients who discontinued DAAs therapy early, before end of treatment (EOT), for any reason developed SVR. As a result, the idea of fractionation of HCV therapy follow-up periods has been considered. In addition, medical practice demands a reliable clinically applied protocol that presents the following advantages: a) eliminating unnecessary extra doses of anti-HCV therapeutic agents (cost-effectiveness); b) reducing medication side effects by shortening the duration of exposure to antivirals; c) recognizing HCV patients who have positive PBMC HCV RNA by PCR at EOT; d) identification of patients who need to extend DAAs therapy beyond the scheduled therapy regimens; and, e) offering a reasonable alarm for early HCV relapse probabilities. Because of the above-mentioned requirements, our study was designed to: a) evaluate anti-HCV treatment responses at frequent time intervals by using both cellular and plasma HCV RNA PCR; b) assess early elimination of HCV infection from both plasma and PBMCs; and, c) address early non-responders to antiviral medications.

\section{Aims of the work}

a. Evaluating response to oral antiviral therapy (OAT) by both single-step reverse transcription (SRT) and PBMC HCV RNA PCR at the end of the $2^{\text {nd }}, 6^{\text {th }}, 10^{\text {th }}, 14^{\text {th }}, 18^{\text {th }}$, and $24^{\text {th }}$ weeks of treatment.

b. Proposing fixed points of HCV therapy termination before EOT course, based upon laboratory evidence during OAT and without interruption of the original therapeutic course.

c. Evaluation of the need to extended HCV treatment beyond the scheduled original therapeutic course, based upon viral clearance from plasma and PBMCs.

d. Predicting posttreatment persistent intracellular $\mathrm{HCV}$ infection in RNA-seronegative patients [posttreatment occult HCV infection (OCIs)], where antiviral therapies are not indicated according to the current guidelines.

e. Proposing additional therapies and/or substitution: ascertaining new avenues to evaluate various antiviral regimens just before or immediately after EOT to address the expected HCV relapse in those who are still HCV-positive at EOT but failed to continue the current or to use a new therapy without any gap between therapeutic regimens.

\section{Methods}

\section{Study subjects}

All study patients ( $n=278$ ) were classified as naïve, compensated, chronic HCV infection who received sofosbuvir, daclatasvir and ribavirin. All cases were diagnosed by PBMC and SRT PCR during the period between February 2015 and June 2017. All of them were Egyptians, who did not travel outside the country and were expected to have the dominantly diagnosed HCV genotype 4 (reported in almost $100 \%$ of domestic $\mathrm{HCV}$ cases in Egypt). Inclusion criteria were: age between 18 and 70 years; no diabetes mellitus and no coinfection with hepatitis B virus or human immunodeficiency virus. All patients had compensated chronic HCV infection and were positive for serum anti-HCV IgG-antibodies (detected by enzyme-linked immunosorbent assay). Exclusion criteria included: HCC (determined by image analysis and negativity for alpha fetoprotein); Child-Pugh class C patients; renal impairment; anemia (hemoglobin $<10 \mathrm{~g} / \mathrm{dL}$ ); and hyperbilirubinemia (serum bilirubin $>2.0 \mathrm{~g} / \mathrm{dL}$ ). Drug interaction with DAAs was verified in each case. Before patient enrollment, ethical committee approval was obtained (registration number 10231; National Research Center). Sample size in each group depended upon availability of subjects that fulfilled the inclusion criteria during study period. Elimination of HCV RNA by OAT was evaluated by SRT and intra-PBMCs HCV RNA PCR at the $2^{\text {nd }}, 6^{\text {th }}, 10^{\text {th }}, 14^{\text {th }}, 18^{\text {th }}$ and $24^{\text {th }}$ weeks.

\section{Real-time PCR for quantification of HCV RNA}

Collection and transport of specimens, RNA isolation and SRT PCR procedure, internal control of the isolated RNA and/or contamination, as well as quantification of HCV PCR were all performed as described by Abd Alla and El Awady ${ }^{4}$ in 2017.

\section{Amplification of intracellular HCV RNA genomes by strand-specific real time (RT)-PCR}

Extraction of RNA from PBMCs: HCV RNA was extracted as described by Abd Alla et al. ${ }^{5}$ A single-step method described by Chomczynski and Sacchi ${ }^{7}$ and modified by Fong et $a .^{8}$ and Goergen ${ }^{9}$ was followed for RNA extraction.

Retrotranscription PCR of sense and antisense strands of HCV RNA: Detection of HCV RNA strands in PBMCs was performed as described by Lohr et al. ${ }^{10}$ Primer sequences $(1 \mathrm{CH}$, $2 \mathrm{CH}, \mathrm{P} 2, \mathrm{P} 3$ and P4) are shown in Table 1. The other steps of Retrotranscription PCR of sense- and antisense-strands of HCV RNA procedure were done as previously reported by Abd Alla and El Awady. ${ }^{4}$

\section{Medicine administration}

The anti-HCV drugs were administered according to guidelines, regarding doses, routes of administration and duration of therapy. ${ }^{11}$ The antiviral therapeutic regimens included sofosbuvir at $400 \mathrm{mg}+$ daclatasvir at $60 \mathrm{mg}+$ weight-based ribavirin daily for 12 to 24 weeks. All study patients $(n=278)$ were submitted to treatment for at least 12 weeks, regardless of their HCV PCR results. During application of CTF2 protocol, the proposed therapy breakpoint at the end of the $2^{\text {nd }}, 6^{\text {th }}$ and $10^{\text {th }}$ weeks was based upon negative SRT and PBMCs HCV RNA PCRs. The actual extension of OAT beyond 12 weeks was justified by persistence of intra-PBMCs HCV RNA strands at the

Table 1. Primer sequences

\begin{tabular}{ll}
\hline Primer name & Sequence $\left(5^{\prime}-3^{\prime}\right)$ \\
\hline $1 \mathrm{CH}$ & ggtgcacggtctacgagacctc \\
$2 \mathrm{CH}$ & aactcatgtcttcacgcagaa \\
P2 & tgctcatggtgcacggtcta \\
P3 & ctttcgcgacccaacactac \\
P4 & agagccatagtggtctgcgg \\
\hline
\end{tabular}


Abd Alla M.D.A et al: Cost-effective HCV treatment by CTF2 protocol

Table 2. Noncumulative individual HCV therapy follow-up fractionation (CTF2) at each point of time by PCR every 4 weeks and at the end of $24^{\text {th }}$ week

\begin{tabular}{|c|c|c|c|c|c|c|c|c|}
\hline \multirow[b]{2}{*}{$\begin{array}{l}\text { PBMCs-PCR } \\
\text { results }\end{array}$} & \multicolumn{8}{|c|}{ CTF2 at each point of time by plasma and PBMC HCV PCRs, $N=278$} \\
\hline & $\begin{array}{l}2^{\text {nd }} \text { week, } \\
N(\%)\end{array}$ & $\begin{array}{l}6^{\text {th }} \text { week, } \\
n(\%)\end{array}$ & $\begin{array}{l}10^{\text {th }} \text { week, } \\
n(\%)\end{array}$ & $\begin{array}{l}14^{\text {th }} \text { week, } \\
n(\%)\end{array}$ & $\begin{array}{l}18^{\text {th }} \text { week, } \\
n(\%)\end{array}$ & $\begin{array}{l}24^{\text {th }} \text { week, } \\
n(\%)\end{array}$ & $\begin{array}{l}\text { EOTSCI, } \\
n(\%)\end{array}$ & $\begin{array}{l}\text { Relapsers, } \\
n(\%)\end{array}$ \\
\hline $\begin{array}{l}\text {-ve cellular } \\
\text { in -ve SRT }\end{array}$ & $61(21.9)$ & $103(37.1)$ & $47(16.9)$ & $18(6.5)$ & $4(1.40)$ & $18(6.5)$ & $0.0(0.0)$ & $0.0(0.0)$ \\
\hline $\begin{array}{l}\text { +ve cellular } \\
\text { in -ve SRT }\end{array}$ & $217(78.1)$ & $114(41.0)$ & $67(24.1)$ & $49(17.63)$ & $45(16.19)$ & $27(9.71)$ & $15(5.4)$ & $11(3.96)$ \\
\hline$p$-value & $<0.00001$ & 0.384 & 0.045 & 0.00007 & $<0.00001$ & 0.214 & 0.00003 & 0.0003 \\
\hline
\end{tabular}

All patients $(N=278)$ had negative serum HCV PCR after 2 weeks of OAT. HCV cure rates as estimated by negative serum PCR are significantly higher than those recognized by cellular PCR at the $2^{\text {nd }}, 10^{\text {th }}, 14^{\text {th }}$ and $18^{\text {th }}$ week $(p<0.05)$. EOT HCV-positive patients and relapsers were addressed by PBMCs PCR but not the serum one $(p<0.001)$ at the end of the $24^{\text {th }}$ week. Total relapsers include $11(3.96 \%)$ positive PBMCs PCR plus positive $1(0.36 \%)$ positive SRT and PBMC PCRs.

Abbreviations: EOT, end of treatment; -ve, negative PCR; +ve, positive PCR; EOTSCI, end of treatment sustained HCV infection; OAT, oral antiviral therapy.

end of $14^{\text {th }}$ and $18^{\text {th }}$ weeks. OAT had to be terminated at the end of the $24^{\text {th }}$ week as recommended by current guidelines. ${ }^{12}$

\section{Statistical analysis}

All tests performed were two-sided and statistical significance was considered at a $p$-value of 0.05 . Methods of statistical analysis of the current dataset were carried out as previously illustrated in Abd Alla et al. ${ }^{5}$

\section{Results}

\section{HCV RNA elimination by OAT as determined by SRT and PBMC PCR at each point of follow-up time}

All studied patients $(n=278)$ who started OAT for chronic $\mathrm{HCV}$ infection had negative SRT PCR after treatment for 2 weeks. Results of CTF2 protocol application were evaluated by testing serum and PBMCs for HCV RNA infection by PCR. As shown in Table 2, application of the CTF2 protocol started at the $2^{\text {nd }}$ week, with assays at 4-week intervals thereafter, up to 24 weeks (the $2^{\text {nd }}, 6^{\text {th }}, 10^{\text {th }}, 14^{\text {th }}, 18^{\text {th }}$ and $24^{\text {th }}$ week). Serum
HCV RNA elimination, as estimated by SRT PCR was significantly higher than posttreatment viral elimination from PBMC, as determined by PBMC PCR, at the end of the $2^{\text {nd }}$ ( 217 vs. $61), 10^{\text {th }}$ (67 vs. 47$), 14^{\text {th }}$ (49 vs. 18 ) and $18^{\text {th }}$ (45 vs. 4 ) weeks $(p<0.05)$. Patients who had PBMC HCV RNA but undetectable plasma viral RNA after the $10^{\text {th }}$ week $(n=67)$ continued the treatment course without interruption and were evaluated by plasma and PBMCs PCR every 4 weeks.

The number of PBMC-positive patients gradually decreased at the end of $14^{\text {th }}$ (18 out of 67 vs. 4 out of 49$), 18^{\text {th }}$ ( 4 out of 49 vs. 18 out of 45$)$, and $24^{\text {th }}$ (18 out of 45 vs. 0.0 out of 27 ) weeks $(p<0.001)$. The non-responders $(n=27)$ included end of treatment sustained HCV infection (EOTSCI) patients $(n=15)$ as described in the CTF2 protocol, in addition to relapsers $(n=12)$. This means that 15 out of these 27 patients had HCV-positive PBMCs PCR all the time from baseline to the end of the study at the $24^{\text {th }}$ week, despite receiving treatment for 24 weeks. The other 12 patients were negative for both SRT and PBMC PCR till the end of the $10^{\text {th }}$ week of the study, and all these 12 patients completed therapy for 12 weeks. At the end of the $24^{\text {th }}$ week, 11 out of these 12 patients showed positive PBMCs PCR and the remaining patient showed positivity for

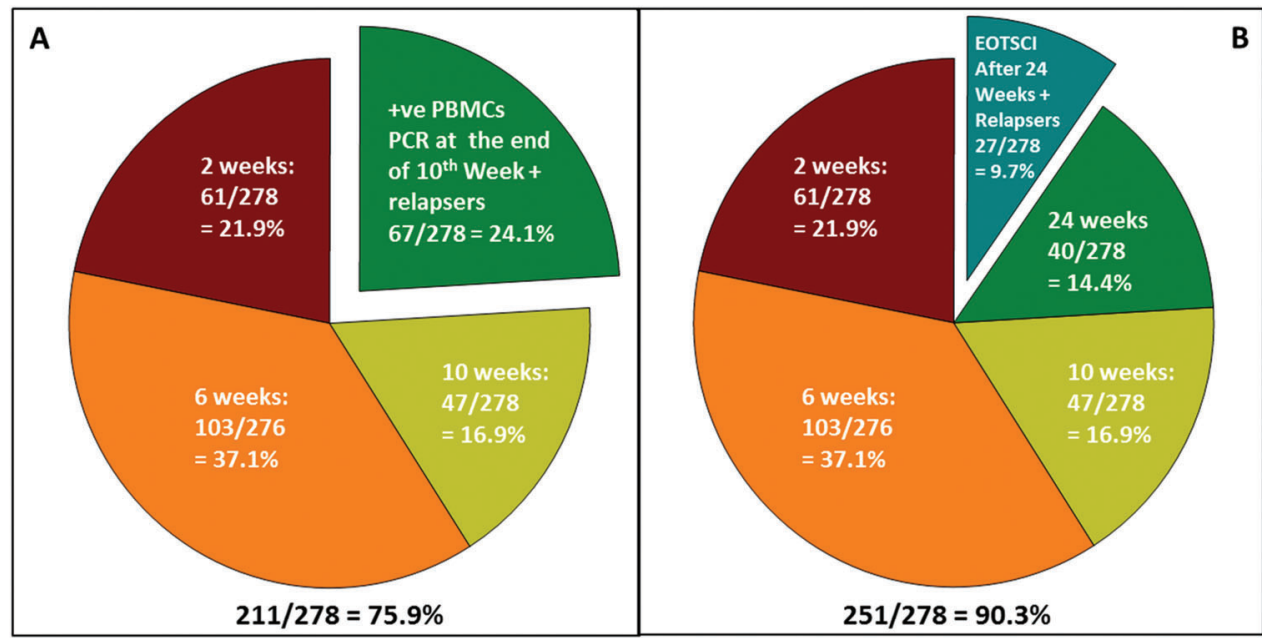

Fig. 1. HCV therapy follow-up fractionation (CTF2) results as evaluated by testing of plasma and PBMC HCV RNA by PCR. Fractionation started at the $2^{\text {nd }}$ week, continued every 4 weeks, and ended at 24 weeks $(2,6,10,14,18$ and 24 weeks). Forty additional cases (14.4\%) showed negative cellular PCR and raised the total HCV RNA $(-)$ rate from $75.9 \%(A)$ at the end of the $10^{\text {th }}$ week to $90.3 \%(B)$ at the end of the $24^{\text {th }}$ weeks $(p<0.00001)$. Abbreviation: EOTSCI, end of treatment sustained HCV infection. 
Abd Alla M.D.A et al: Cost-effective HCV treatment by CTF2 protocol

Table 3. Results of sequential cumulative negative PBMC HCV RNA PCR results at each follow-up point

\begin{tabular}{|c|c|c|c|c|c|c|c|}
\hline \multirow[b]{2}{*}{$\begin{array}{l}\text { PBMCs PCR } \\
\text { results }\end{array}$} & \multicolumn{7}{|c|}{ CTF2 protocol application results at each point of time by HCV RNA, $N=278$} \\
\hline & $\begin{array}{l}2^{\text {nd }} \text { week, } \\
n(\%)\end{array}$ & $\begin{array}{l}6^{\text {th }} \text { week, } \\
n(\%)\end{array}$ & $\begin{array}{l}10^{\text {th }} \text { week, } \\
n(\%)\end{array}$ & $\begin{array}{l}14^{\text {th }} \text { week, } \\
n(\%)\end{array}$ & $\begin{array}{l}18^{\text {th }} \text { week, } \\
n(\%)\end{array}$ & $\begin{array}{l}24^{\text {th }} \text { week, } \\
n(\%)\end{array}$ & $\begin{array}{l}\text { EOTSCI }+ \\
\text { Relapse, } n(\%)\end{array}$ \\
\hline $\begin{array}{l}\text {-ve cellular in } \\
\text {-ve-SRT }\end{array}$ & $61(21.9)$ & $164(59.0)$ & $211(75.9)$ & $229(82.37)$ & $233(83.81)$ & $251(90.29)$ & $0(0.0)$ \\
\hline $\begin{array}{l}\text { +ve cellular in } \\
\text {-ve-SRT }\end{array}$ & $217(88.1)$ & $114(41.0)$ & $67(24.1)$ & $49(17.63)$ & $45(16.19)$ & $27(9.71)$ & $26(9.36)$ \\
\hline$p$-value & $<0.00001$ & 0.00003 & $<0.00001$ & $<0.00001$ & $<0.00001$ & $<0.00001$ & 0.00001 \\
\hline
\end{tabular}

After 2 weeks of OAT administration, all patients $(N=278)$ had negative HCV SRT PCR. At the end of the $2^{\text {nd }}$ week, patients were subdivided into PBMC HCV RNA $(-)$ ( $\left.n=61\right)$ and PBMC HCV RNA $(+)(n=217)$ as diagnosed by PBMCs PCR $(p<0.00001)$. Starting from the end of the $6^{\text {th }}$ week of OAT until the end of the $24^{\text {th }}$ week, PBMC HCV RNA $(-)$ rates are significantly higher than the PBMC $(+)$ ones $(p<0.0001)$. The non-responders that include both EOT patients with positive HCV infection and relapsers are significantly recognized by PBMC HCV RNA $(p<0.0001)$. Total non-responders include $26(9.36 \%)$ PBMC HCV RNA(+) plus positive 1 (0.36\%) for both SRT and PBMCs HCV RNA.

Abbreviation: EOTSCI, end of treatment sustained HCV infection.

both SRT and PBMC PCRs. So, at the end of the $10^{\text {th }}$ week, PBMCs PCR succeeded in recognizing 67 out of 278 and failed to detect 12 out of 211 ( $p<0.0001$ ).

All non-responders were addressed by positive PBMC HCV RNA PCR $(p<0.001)$, and one case tested positive by both SRT and PBMC HCV RNA PCR. Fig. 1 demonstrates the results of the extended therapy after the scheduled 12 weeks in patients who tested positive for PBMC HCV RNA. It shows that 40 out of 278 additional cases (14.4\%) tested negative for PBMC HCV RNA between the ends of the $14^{\text {th }}$ and $24^{\text {th }}$ weeks compared to 211 out of $278(75.9 \%)$ patients who did not receive prolonged treatment. This resulted in improving the total cure rate from $75.9 \%$ (Fig. $1 \mathrm{~A}$ ) at the end of the $10^{\text {th }}$ week to $90.3 \%$ (Fig. 1B) at the end of $24^{\text {th }}$ week ( $p<$ 0.00001).

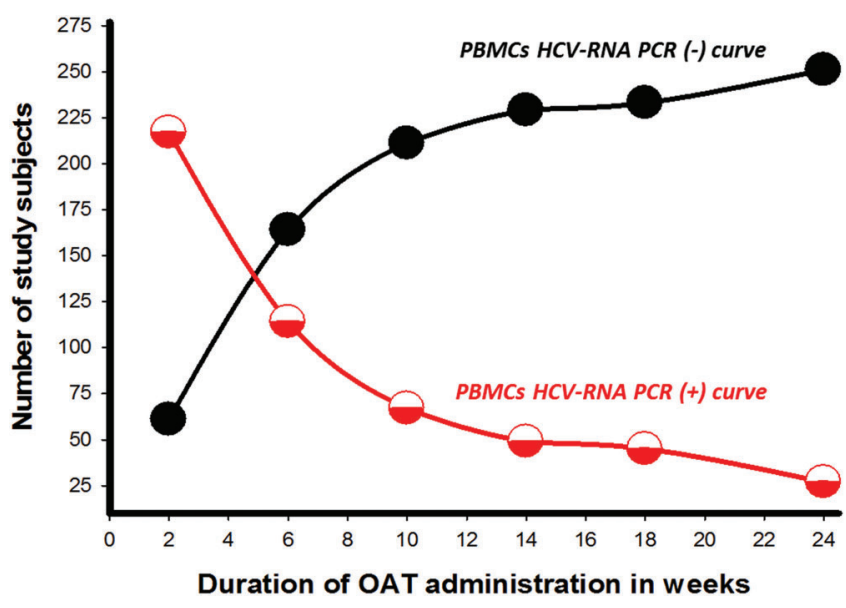

Fig. 2. Follow-up of anti-HCV OAT outcomes by PBMCs RNA PCR(-) compared to PBMCs RNA PCR(+) during application of the CTF2-protocol. $P$-values showed significant rises in PBMCs RNA PCR $(-)$ (black curve) compared to the drops in PBMCs RNA PCR $(+)$ (red curve) viral elimination upon comparing the $2^{\text {nd }}$ week with the $6^{\text {th }}$ week $(p<0.00001)$, the $6^{\text {th }}$ week with the $10^{\text {th }}$ week $(p<$ 0.001 ), and the $18^{\text {th }}$ week with the $24^{\text {th }}$ week $(p>0.05)$, and insignificant changes on comparing the $10^{\text {th }}$ week with the $14^{\text {th }}$ week $(p=0.07)$, and the $14^{\text {th }}$ week with the $18^{\text {th }}$ week $(p=0.73)$. Significant rises in the PBMCs RNA PCR $(-)$ curve compared to the drops in PBMCs RNA PCR $(+)$ curve were noted on comparing both the $10^{\text {th }}$ and $14^{\text {th }}$ weeks with the $24^{\text {th }}$ week $(p<0.00001$ and $<0.01$ respectively).

\section{Cumulative elimination of plasma and intracellular HCV infections by OAT during application of the CTF2 protocol}

The cumulative cure rates as diagnosed by PBMC HCV RNA(+) and PBMC HCV RNA(-) after treatment with OAT are illustrated in Table 3 . All the patients $(n=278)$ showed negative SRT HCV PCR results after 2 weeks of receiving OAT. According to the PBMCs results, the patients were divided into PBMC HCV RNA $(-)$ responders $(n=61)$ and PBMC RCV RNA $(+)$ non-responders $(n=217)(p<0.001)$ at the end of the $2^{\text {nd }}$ week. Starting from the end of the $6^{\text {th }}$ week until the end of the $24^{\text {th }}$ week of the CTF2 protocol application, PBMC HCV RNA $(-)$ (164 at the $6^{\text {th }}$ week, 211 at the $10^{\text {th }}$ week, 229 at the $14^{\text {th }}$ week, 233 at the $18^{\text {th }}$ week, and 251 at the $24^{\text {th }}$ week) were significantly increased compared to the PBMC $\mathrm{HCV}$ RNA(+) $\left(114\right.$ at the $6^{\text {th }}$ week, 67 at the $10^{\text {th }}$ week, 49 at the $14^{\text {th }}$ week, 45 at the $18^{\text {th }}$ week, and 27 at the $24^{\text {th }}$ week) $(p<0.0001)$. The same table also shows both HCVrelapsers and EOTSCI non-responders.

All non-responders were identified only by PBMC HCV RNA PCR compared to plasma HCV RNA PCR $(p<0.0001)$. The relationship between the gradual increase in PBMC HCV $\mathrm{RNA}(-)$ responders and gradual decrease in PBMC HCV $\mathrm{RNA}(+)$ non-responders upon applying the CTF2 protocol is illustrated in Fig. 2. There were significant rises in the number of PBMC HCV RNA $(-)$ and decreases in the number of PBMC HCV RNA $(+)$ upon comparison at the end of the $2^{\text {nd }}$ week with the $4^{\text {th }}$ week $(p<0.00001)$, $6^{\text {th }}$ week with $10^{\text {th }}$ week $(p<$ $0.001)$, and $18^{\text {th }}$ week with the $24^{\text {th }}$ week $(p<0.05)$ but

Table 4. Role of PBMC HCV RNA in identification of EOTSCI as diagnosed by intracellular HCV RNA after OAT

\begin{tabular}{lll}
\hline PCR Results & HCV RNA (-) & HCV RNA (+) \\
\hline SRT PCR, $n=266$ & $266 / 266(100 \%)$ & $0.0(0.0 \%)$ \\
PBMC HCV & $251 / 266$ & $15 / 266$ \\
RNA,$n=251$ & $(94.36 \%)$ & $(5.64 \%)$ \\
$p$-value & 0.000049 & \\
\hline
\end{tabular}

Responses to OAT in patients who presented with EOTSCI and had positive PBMC HCV RNA infection $(n=15)$ significantly reduced the total EOT response rate from 266 (detected by SRT PCR) to 251 (detected by PBMCs PCR) $(p<0.0001$ ). 
insignificant changes when comparing the $10^{\text {th }}$ week with the $14^{\text {th }}$ week $(p=0.07)$, and the $14^{\text {th }}$ week with the $18^{\text {th }}$ week $(p$ $=0.73)$. Significant rises in frequencies of PBMC HCV RNA $(-)$ response compared to the decreases in PBMC HCV RNA(+) response by PBMC HCV RNA PCR were noted upon comparing both the $10^{\text {th }}$ and $14^{\text {th }}$ weeks with the $24^{\text {th }}$ week $(p<0.00001$ and $<0.01$ respectively).

\section{Identification of non-responders (EOT HCV RNA-positive and relapsers) as tested by SRT and PBMC HCV RNA PCR}

Table 4 presents the results of non-responders who remained positive for PBMC RNA up to the EOT. Although 266 patients had negative PCR results in their plasma at EOT with OAT, only $251(94.36 \%)$ achieved undetectable HCV RNA in PBMC. The residual 15 cases $(5.64 \%)$ remained positive for intra-PBMCs HCV RNA. These 15 patients who were diagnosed by PBMC PCR lowered the EOT response rate from 266 to 251 ( $p<0.0001$ ). Fig. 3 illustrates the significance of detecting HCV RNA in PBMCs over plasma HCV RNA, where 27 out of 278 (9.71\%) were non-responders to OAT at 12-week SVR. The total number of SVR after OAT was significantly higher when diagnosed by plasma SRT PCR $(n=277 / 288,99.64 \%)$ compared to PBMC HCV RNA $(n=251 / 278,90.29 \%)(p=0.000046)$.

\section{Algorithmic model of the proposed CTF2 protocol based upon combined testing with SRT and PBMCS-PCR}

Fig. 4 demonstrates a proposed CTF2 protocol that evaluates OAT outcomes. Application of the CTF2 protocol will be subjected to further research before it is validated for clinical practice. Algorithms are self-explanatory and clarify stepby-step the application of the CTF2 protocol over time. The core idea behind the reported six algorithms, each in a single cell, is the quantitative control of antiviral therapy by recognizing the shortest most effective therapeutic durations that lead to potential SVR. As illustrated in each algorithm, SRT and PBMC PCRs were performed after the $14^{\text {th }}$ tablet of each DAAs medicine and gave a grace period of 2 weeks to eval- uate patient cellular and SRT-PCRs results during OAT. When both SRT and intra-PBMC PCRs became negative, the patient could stop treatment at the end of the grace period. Contrarily, patients who still have positive PCR during grace periods will continue OAT without interruption until the end of 24-week course of treatment.

\section{Discussion}

Early elimination of HCV RNA from plasma in $100 \%$ of the studied cases after 2 weeks of therapy was reported in the current study. However, the actual clearance of viral RNA from both plasma and PBMCs at the same time was observed only in $21.9 \%$. Despite the recorded disparity between serum and PBMC HCV RNA results in the current dataset, the authors followed treatment guidelines in all cases, including those who achieved early cellular clearance of viral infection $(21.9 \%)$ and, therefore, completed the scheduled antiviral therapy for at least 12 weeks. ${ }^{11}$ This finding would explain the occasional reporting of early occurrence of SVR after anti-HCV OAT for a few weeks.

As during practice in infectious disease clinics, sporadic cases occasionally presented with side effects of anti-HCV medicines that mandated premature discontinuation of medications after 3 weeks or less. In a long-term perspective, those cases demonstrated virus-free plasma and PBMC that did not need reintroduction of anti-HCV OAT. These selected cases had variable grades of liver cirrhosis, but liver functions were compensated without encephalopathy or HCC manifestations (unpublished data). This early SVR associated with the currently used OAT may be considered as either dramatic or rapid response, a term that needs further evaluation. Based on the current findings, the term 'HCV therapy follow-up fractionation' (the CTF2) protocol is proposed. The proposed CTF2 protocol allows for evaluation of HCV eradication after the first 2 weeks, and then every 4 weeks by plasma and cellular PCR. The expected advantages of the currently proposed CTF2 protocol included reducing medication side effects by shortening the duration of exposure to anti-HCV OAT, eliminating unnecessary extra doses of anti-HCV OAT agents (cost-effectiveness), recognizing the non-responders
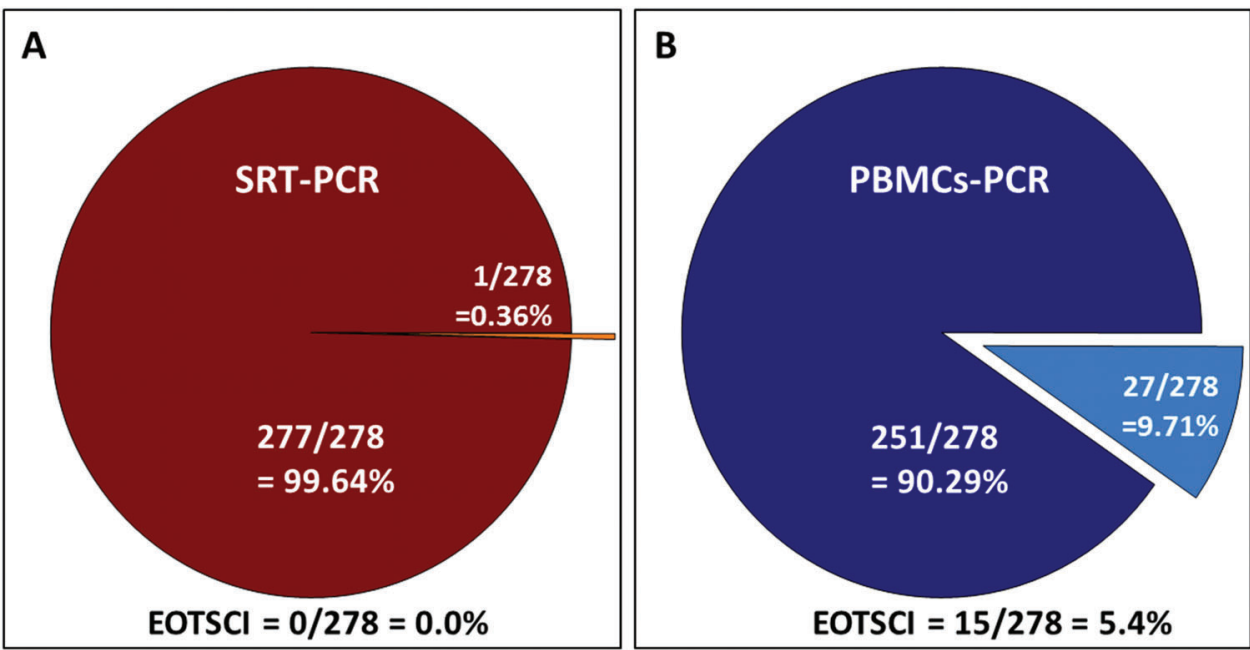

Fig. 3. Comparison of PBMCs and SRT PCRs yields after OAT at the end of the CTF2 protocol application including 12-week SVR. The total number of HCV RNA PCR(+) after OAT was significantly higher on using PBMCs PCR $(n=27)$ compared to SRT PCR $(n=1)(p<0.0001)$. 


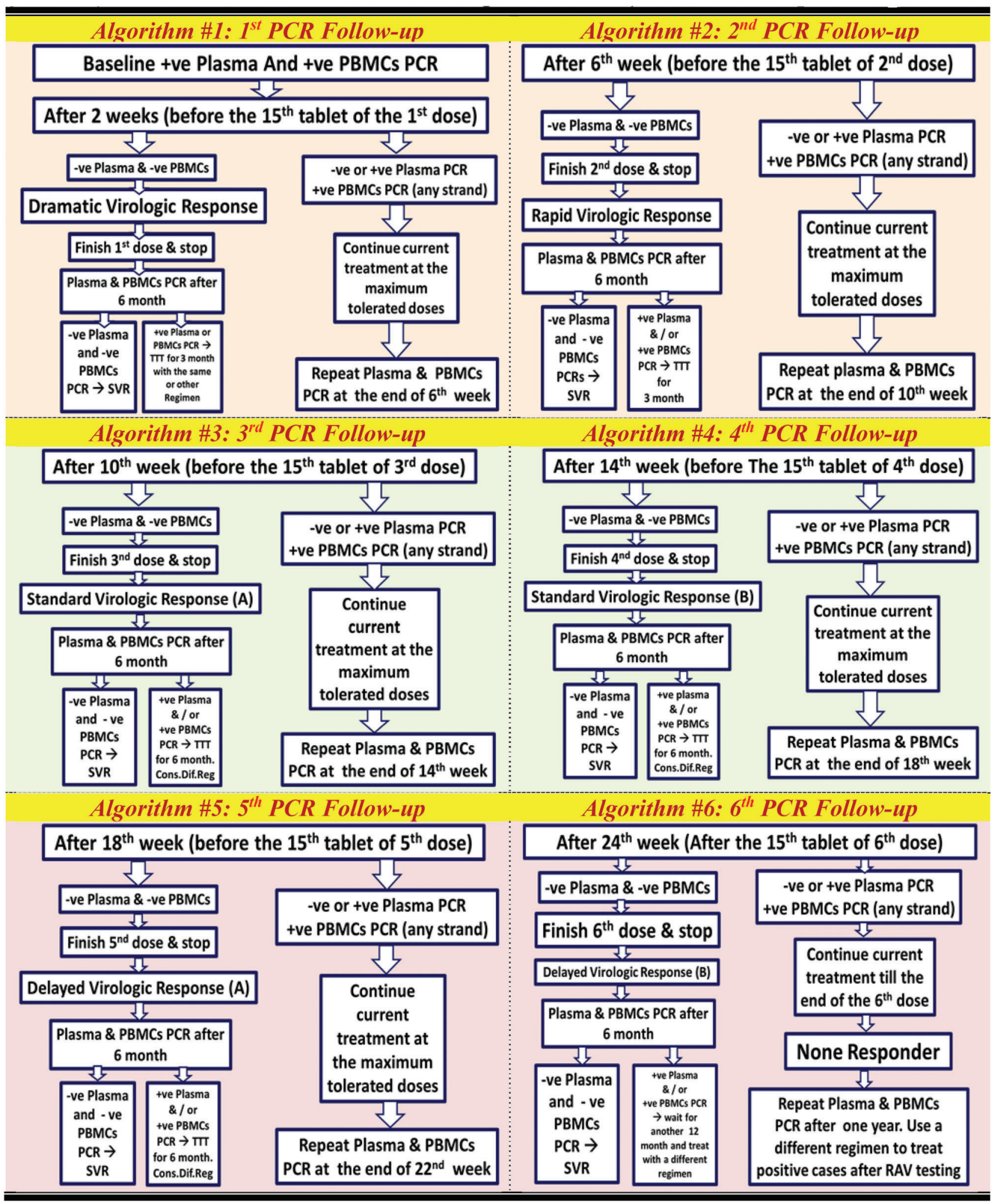

Fig. 4. Proposed algorithms for HCV therapy follow-up fractionation (CTF2) protocol as guided by serum and PBMC HCV PCR during the use of any antiviral therapeutic regimen. Algorithms (1-6) describe the relationship of OAT administration periods with intra-PBMC clearance of HCV RNA strands that indicates a high probability of cure. Abbreviations: +ve, positive PCR; -ve, negative PCR; Con. Dif. Reg., consider different regimen; $T T$, treatment. 
before anti-HCV EOT course, continuing treatment of nonresponders without therapy interruption gaps, and early expectation of HCV serologic relapse.

The current dataset confirmed the occurrence of occasional complete cure (i.e. SVR) in some patients who were exposed to anti-HCV OAT for shorter periods than originally scheduled, before completing therapy. None of the $21.9 \%$ cases that showed PBMC viral clearance had HCV RNA in their plasma or PBMCs throughout the treatment course or during evaluation of SVR. These results would encourage researchers to further study PBMC or plasma HCV RNA relapse after interrupting the antiviral therapy at points where HCV RNA disappeared concomitantly from PBMC and plasma without proceeding to the EOT course.

Recognition of intracellular HCV RNA strand infections by PBMCs PCR during or just before EOT with any of the currently used OAT regimens (e.g., sofosbuvir and daclatasvir with ribavirin for 3 months) is disturbing and needs further research. During application of the CTF2 protocol, herein, we did not impose contradictions with the currently approved guidelines for OAT. ${ }^{11}$ Anti-HCV OAT continuation for an extra 4 to 12 weeks according to PBMCs PCR results helped reach the SVR without discontinuation gaps that may otherwise deprive a patient of the chance to achieve SVR. Theoretically, changes in therapeutic regimens by addition and/or substitution of other antiviral agents according to treatment course requirement before EOT would be a feasible option during the CTF2 protocol application. The decision of continuing the selected OAT for up to a maximum of 24 weeks in certain patients has become feasible because of the significantly increased number of patients who achieved SVR upon extension of medication. Flexibility of making minor changes in treatment regimens prior to or at EOT is a possibility and adds clinically applied advantages to HCV infection management.

The current study illustrates six algorithms, each defining the relationship between duration of treatment at one time point and dual disappearance of viral RNA from plasma and PBMCs at the end of the $2^{\text {nd }}, 10^{\text {th }}, 14^{\text {th }}, 18^{\text {th }}$ and $24^{\text {th }}$ weeks respectively. There are several future studies on the applications of the CTF2 protocol, such as determining the emergence of resistance-associated substitutions (RAS) and relapse at any of the proposed breakpoints. Given the fact that some of the patients were obligated to completely interrupt antiHCV OAT early during treatment was associated with SVR for more than 1 year, potentiates the need for researchers to consider studying applications of the CTF2 protocol in depth during clinical practice. It should be noted that one of the major advantages of the CTF2 protocol is cost-effectiveness. In the USA, Canada, and European countries, the 12-week DAAs course is very costly, and seldom afforded by patients without health insurance or special healthcare aid programs. Studying probabilities of minimizing the cost of anti-HCV OAT to one-third or to one-half of the originally planned course prices via the application of the CTF2 protocol would encourage the private sectors to consider reducing the burden of treatment expenses.

One of the current study goals was to evaluate HCV therapy follow-up fractionation results when treatment guidelines are not helpful. It was reported in a previous study that elimination of intracellular infection would be associated with a drop in liver cirrhosis and subsequent decrease in comorbidity of end-stage liver disease. ${ }^{4,5}$ Since one of the main indications of OAT is to ensure early HCV elimination from both plasma and PBMCs, and subsequently to arrest liver fibrosis progression, the current CTF2 protocol seems to achieve this goal by the systematic evaluation of anti-HCV OAT outcome. The current data clearly show that continuation of OAT beyond the 12 weeks until elimination of the previously approved intracellular HCV RNA infection is successful. ${ }^{12,13}$ The CTF2 protocol described herein will not only satisfy patient needs to eliminate the intracellular HCV RNA but also will help to unify the terminology of persistent RNA in cells as a relapse but as a nonresponse. Further research is required to validate the treatment fractionation into therapy follow-up breakpoints as identified by the CTF2 protocol until both plasma and PBMC HCV RNA became negative.

The current CTF2 protocol recommends extension of OAT beyond the scheduled course of treatment based upon persistence of HCV RNA in PBMCs of seronegative patients. OAT continuation for a maximum of 24 weeks is justified by the significant association with increased SVR in nonresponders after 12 weeks of therapy. ${ }^{4,5}$ The CTF2 protocol provides the advantage of recognition of non-responders at EOT and early identification of relapse. It is strongly recommended by the current study authors to further evaluate using the proposed CTF2 protocol in future research.

Limitations of our work were related to the reported HCV PBMCs PCR(-) in 12 out of 211 patients during the first 12 weeks of OAT, and then identifying them later as relapsers at the end of the $24^{\text {th }}$ week. In fact, these 12 patients may be non-responders and the PBMC HCV RNA PCR could not recognize them earlier before completing the 12 weeks of OAT. This limitation might be related to the occasionally decreased availability of the infected mononuclear cells in patient circulation for a while after completing the treatment course. ${ }^{6,13}$ In addition, our design did not offer enough time to evaluate the association of HCV RNA PBMC(+) SRT(-) PCR with seroconversion. So, the frequency of PBMC HCV RNA PCRdependent relapse in the current study $(10.3 \%)$ was higher than SRT PCR-dependent relapse that was reported in registration trials because PBMC HCV RNA relapse was identified early, and maybe more time is required to see increasing rates of viral RNA seroconversions. Other minor limitations included the prohibitive cost and the decreased availability of PBMCs PCR as a convenient diagnostic procedure because it is not yet well known to practitioners in HCV endemic areas.

In conclusion, we report marked disparity between SRT and PBMCs PCRs during evaluation of oral anti-HCV therapeutic efficacies. The achievement of earlier elimination of plasma and cellular HCV infection by antiviral therapy can be accomplished as identified by application of the CTF2 protocol and is expected to be associated with reducing treatment cost in future. Therapy extension beyond the scheduled treatment course is productive and leads to increasing SVR rates through minimizing the number of non-responders. Finally, application of the CTF2 protocol grants early identification of non-responders and potential relapsers in HCV RNA seronegative cases.

\section{Acknowledgments}

Financial support for this study was provided by the Faculty of Medicine at Al-Azhar University. Academic and technical support from the National Research Center (Cairo, Egypt) and the Academy of Scientific Research and Technology Development Fund (Grant No. 3365) are appreciated. We 
gratefully acknowledge the Herman Lopata Chair in Hepatitis Research for help and support of this study.

\section{Conflict of interest}

The authors have no conflict of interests related to this publication.

\section{Author contributions}

Study design, patient management, data analysis and writing of the manuscript (MDAA), patient recruitment (SE); writing of the manuscript (RE, GW), performance of the PCR screening (MEA, RD).

\section{References}

[1] MABROUK M, Salama R, Gamal H, Din EL, DIN HGE, Baseline Predictors of Sustained Virological Response to Pegylated Interferon and Ribavirin in Egyptian Patients Infected with Viral Hepatitis C. The Medical Journal of Cairo University 2013;81:519-523.

[2] Castillo I, Pardo M, Bartolomé J, Ortiz-Movilla N, Rodríguez-Iñigo E, de Lucas $S$, et al. Occult hepatitis $C$ virus infection in patients in whom the etiology of persistently abnormal results of liver-function tests is unknown. J Infect Dis 2004;189:7-14. doi: 10.1086/380202.

[3] Wasmuth $\mathrm{HE}$, Trautwein C. Prediction of fibrosis progression in hepatitis $\mathrm{C}$ infection: are genetics ready for clinical use? J Hepatol 2011;55:3-4. doi: 10. 1016/j.jhep.2011.02.003.

[4] Abd Alla MDA, El Awady MK. Hepatitis C virus RNA strands detection in peripheral blood mononuclear cells legitimizes virus eradication in negative serum PCR naïve and post-treatment patients. J Clin Transl Hepatol 2017;5: 1-8. doi: 10.14218/JCTH.2016.00054

[5] Abd Alla MDA, Elibiary SA, Wu GY, El-Awady MK. Occult HCV infection (OCI) diagnosis in cirrhotic and non-cirrhotic naïve patients by intra-PBMC nested viral rNA PCR. J Clin Transl Hepatol 2017;5:319-326. doi: 10.14218/JCTH. 2017.00034.

[6] Castillo I, Bartolomé J, Quiroga JA, Barril G, Carreño V. Diagnosis of occult hepatitis $C$ without the need for a liver biopsy. J Med Virol 2010;82:15541559. doi: $10.1002 / j m v .21866$

[7] Chomczynski P, Sacchi N. Single-step method of RNA isolation by acid guanidinium thiocyanate-phenol-chloroform extraction. Anal Biochem 1987 162:156-159. doi: 10.1006/abio.1987.9999.

[8] Fong TL, Shindo M, Feinstone SM, Hoofnagle JH, Di Bisceglie AM. Detection of replicative intermediates of hepatitis $C$ viral RNA in liver and serum of patients with chronic hepatitis C. J Clin Invest 1991;88:1058-1060. doi: 10.1172/JCI115368.

[9] Goergen B, Jakobs S, Symmons P, Hornes E, Meyer zum Büschenfelde $\mathrm{KH}$ Gerken G. Quantitation of HCV-replication using one-step competitive reverse transcription-polymerase chain reaction and a solid phase, colorimetric detection method. J Hepatol 1994;21:678-682. doi: 10.1016/ S0168-8278(94)80118-5.

[10] EASL Recommendations on Treatment of Hepatitis C 2016. J Hepatol 2017 66:153-194. doi: 10.1016/j.jhep.2016.09.001.

[11] Rodríguez-Iñigo E, Casqueiro M, Navas S, Bartolomé J, Pardo M, Carreño V. Fluorescent "in situ" hybridization of hepatitis C virus RNA in peripheral blood mononuclear cells from patients with chronic hepatitis C. J Med Virol 2000;60:269-274. doi: 10.1002/(SICI)1096-9071(200003)60: 3<269::AID-JMV4>3.0.CO;2-1.

[12] El-Awady MK, Ismail SM, El-Sagheer M, Sabour YA, Amr KS, Zaki EA. Assay for hepatitis $C$ virus in peripheral blood mononuclear cells enhances sensitivity of diagnosis and monitoring of $\mathrm{HCV}$-associated hepatitis. Clin Chim Acta 1999;283:1-14. doi: 10.1016/S0009-8981(99)00007-8.

[13] Xu DZ, Xie Y, Li ZQ. Clearance of HCV RNA in peripheral blood mononuclear cell as a predictor of response to antiviral therapy in patients with chronic hepatitis C. Hepatobiliary Pancreat Dis Int 2005;4:550-553. 